\title{
Treatment of Severe Open Bite Using Buccal and Palatal Miniscrew: A 5-Year Follow-up
}

\section{ISSN: 2637-7764}

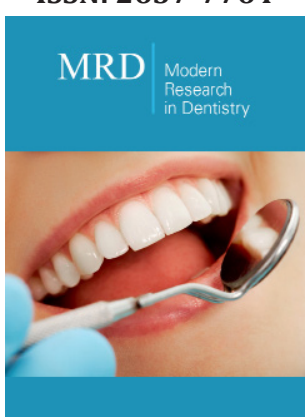

*Corresponding author: Aylin Pasaoglu Bozkurt, Assistant of Professor, Beykent University Dentistry Faculty Department of Orthodontics, Buyukcekmece, 34550, Istanbul, Turkey

\section{Submission: 望 February 07, 2020}

Published: 僵 February 25, 2020

Volume 5 - Issue 1

How to cite this article: Aylin Pasaoglu Bozkurt, Furkan Dindaroglu, Servet Dogan. Treatment of Severe Open Bite Using Buccal and Palatal Miniscrew: A 5-Year Follow-up. Mod Res Dent. 5(1). MRD.000601.2020.

DOI: 10.31031/MRD.2020.05.000601

Copyright@ Aylin Pasaoglu Bozkurt, This article is distributed under the terms of the Creative Commons Attribution 4.0 International License, which permits unrestricted use and redistribution provided that the original author and source are credited.

\author{
Aylin Pasaoglu Bozkurt ${ }^{1 *}$, Furkan Dindaroglu ${ }^{2}$ and Servet Dogan ${ }^{3}$ \\ ${ }^{1}$ Assistant Professor, Department of Orthodontics, Faculty of Dentistry, Beykent University, \\ Istanbul, Turkey \\ ${ }^{2}$ Associate Professor, Department of Orthodontics, Faculty of Dentistry, Ege University, Izmir, \\ Turkey \\ ${ }^{3}$ Professor, Department of Orthodontics, Faculty of Dentistry, Ege University, Izmir, Turkey
}

\begin{abstract}
s
Objective: High-angle cases frequently show a vertical growth pattern, high mandibular plane angle and a long lower facial height. Such cases are referred to as skeletal open bite, and are most difficult to treat orthodontically, they may require skeletal anchorage or surgery. The aim of this case report is to highlight the importance of miniscrews in a severe open bite case.
\end{abstract}

Method: Patient presenting with anterior and lateral open bite, long face syndrome, respiratory problems (13 years 2 months) admitted to the clinic for orthodontic evaluation. She had severe crowding, cl II skeletal relationship, proclaimed incisor, anterior and lateral open bite and gummy smile. Patient was informed about surgery, but she refused. At the beginning of the treatment leveling was carried out with extraction of four first premolars. After one appointment of applying the stabilization arc wire (17x25 SS) 4 miniscrews ( 2 for buccal, 2 for palatal side) was used for intrusion of maxillary molars. Also 1 miniscrew was inserted between 11-21 for controlling the elongation of incisors because of gummy smile.

Result: After six months of intrusion molars, mandibular autorotation was achieved. Leveling and alignment was completed. Class I molar and canine relationship were achieved. Although we used full arch wire intrusion mechanics, gummy smile didn't get worse. Profile was improved.

Conclusion: Miniscrews are very important in orthodontic treatment for patients who refuse to have surgery. Although we obtain more aesthetic results in surgery, also miniscrews might be used for the comprehensive treatment.

Keywords: Open bite; Skeletal class II; Orthodontic treatment; Miniscrew

\section{Introduction}

Being without vertical overlap relationship between upper and lower teeth when the jaws in the centric occlusion is defined as open bite. Genetic and environmental factors can be reason for developing anterior open bite. Sucking habits problems (finger and thumb), tongue posturing, respiratory problems related to conditions such as allergies, adenoids and tonsils, and mouth breathing can be counted as environmental factors [1]. Patients who show an excess of anterior vertical facial growth, they are more prone to have anterior open bite. These skeletal open bites cases are most difficult to treat orthodontically, they may require orthognathic surgery [2]. Orthognathic surgery may provide satisfactory results but, the complication possibility, risks, and high rate of charges of surgery have canalized doctors for searching an alternative treatments procedure [3-5]. Miniscrews can be used in orthodontics for space closure, space opening, intrusions, molar distalization, molar mesialization [69]. Miniscrews were preferred because of easy insertion and removal without irreversible changes, possibility of immediate loading, low cost of the instruments, and shorter duration time of treatment $[7,10]$.

Posterior impaction of dentition and open-bite correction through upward and forward mandibular autorotation can be done by orthodontic miniscrews [11]. Autorotating the mandible in a counterclockwise direction, can provide closing the open bite, and reducing the anterior facial height without any surgical treatment [12]. The aim of this case report is to show an alternative method to provide the demands of a severe skeletally open bite patient who refuse to have surgery and also to highlight the importance of miniscrews in patients with gummy smile. 


\section{Diagnosis and etiology}

Transfer patient who was 13 years 2 months presenting with anterior and lateral open bite, long face syndrome, respiratory problems came to the Orthodontic Department of Ege University for orthodontic evaluation. She had already lower brackets when she came to our clinic. Her chief complaint was inability to close her mouth. During swallowing and conversation tongue-thrust wasn't observed. She had a symmetrical face, bigonial and bizygomatic width proportion was harmonic. Lower third of her face was longer than the other parts (Figure 1). There was no midline discrepancy. She had gummy smile and extensive upper incisors exposure. She had a convex profile, normal nasolabial angle, shallow labiomental sulcus, normal cheekbone contour. Intraoral and dental cast examinations showed severe crowding, class I molar relationship, proclined incisor, high level upper canine, anterior and lateral open bite. The teeth were in contact at the second molars for both right and left side.

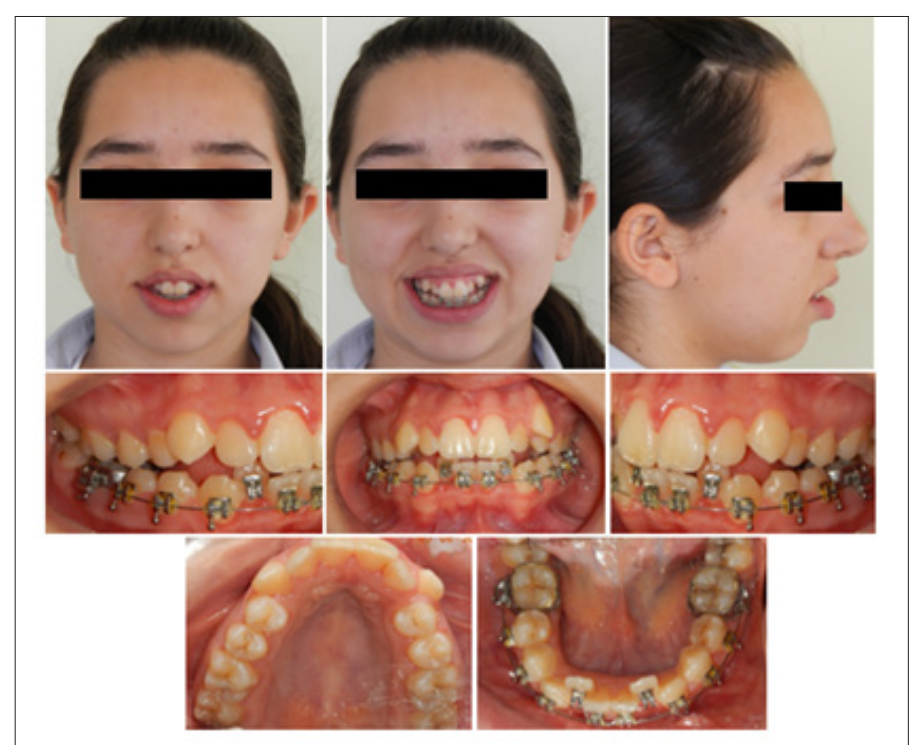

Figure 1: Pretreatment photographs.

Hays nance and bolton analysis were done to define the space requirement (Figure 2). We need $9 \mathrm{~mm}$ in the upper arch and 8,5 in the lower arch to relieve the crowding. The periodontal hygiene status was moderate. Panoramic radiography revealed no radiographic lesion or resorption around the roots (Figure 3). The pretreatment measurements showed, a class II skeletal relationship (ANB: 6.3). Maxillary (U1-SN: 115.1) and mandibular incisor inclinations (IMPA, L1-MP: 103.1) were out of normal limits (Figure 4) (Table 1). Based on these findings' patient had skeletal class II bimaxillary retrognathia, dental class I molar and canine relationship, skeletal open bite with high angle-vertical growth pattern, increased upper incisor inclination, retrusive upper and lower soft tissue, crowding, gummy smile and convex profile.

Table 1: Pretreatment and post-treatment cephalometric measurements.

\begin{tabular}{|c|c|c|c|c|c|}
\hline Measurement & Norm & Pretreatment & Before Intrusion & After 6 Months of Intrusion & Post-treatment \\
\hline SNA (o) & $83.6 \pm 6.4$ & 75.8 & 77.3 & 78.8 & 80.6 \\
\hline SNB (o) & $80.8 \pm 6.0$ & 69.5 & 72.2 & 74.2 & 75.8 \\
\hline ANB (o) & $2.8 \pm 3.8$ & 6.3 & 5.1 & 4.6 & 4.8 \\
\hline Witsappraisal (mm) & $-1 \pm 1.0$ & 5.6 & 4.8 & 0.6 & -2 \\
\hline SN to MP (o) & $26.6 \pm 10.6$ & 42.8 & 42 & 40 & 38.2 \\
\hline U1 to $\mathrm{SN}(\mathrm{o})$ & $105.0 \pm 10.6$ & 115.1 & 106.2 & 95 & 98.6 \\
\hline L1 to $\mathrm{MP}(\mathrm{o})$ & $4.3 \pm 11.1$ & 93.3 & 92.2 & 92.9 & 91 \\
\hline Mx Occlusal Plane & 95.6 & 103.1 & 102 & 99.6 & 99.4 \\
\hline Upper lip to E-line (mm) & $-3.2 \pm 2.0$ & 2.9 & -3.1 & -3.3 & -3.6 \\
\hline Lower lip to E-line (mm) & $3.0 \pm 2.0$ & -2 & -1.2 & -0.6 & 1 \\
\hline Nasolabial Angle(o) & $90-110$ & 98 & 98 & 99 & 99 \\
\hline
\end{tabular}




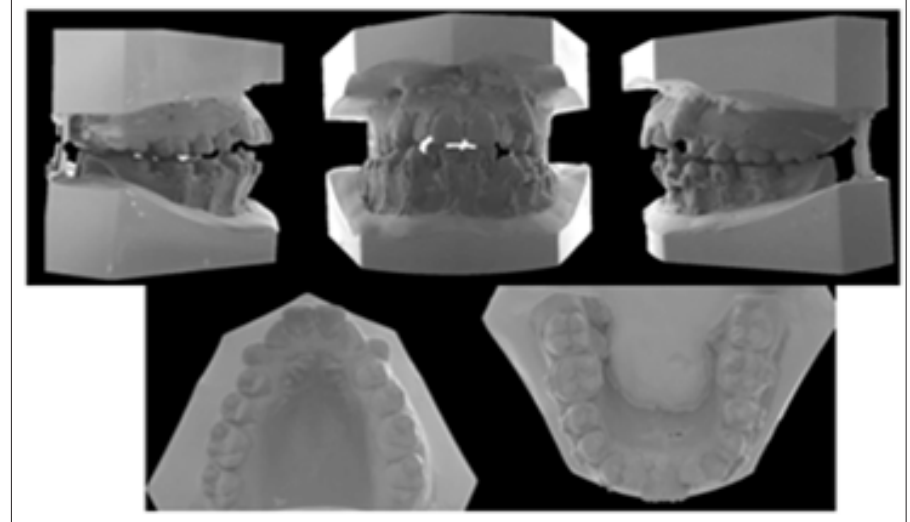

Figure 2: Pretreatment dental casts.

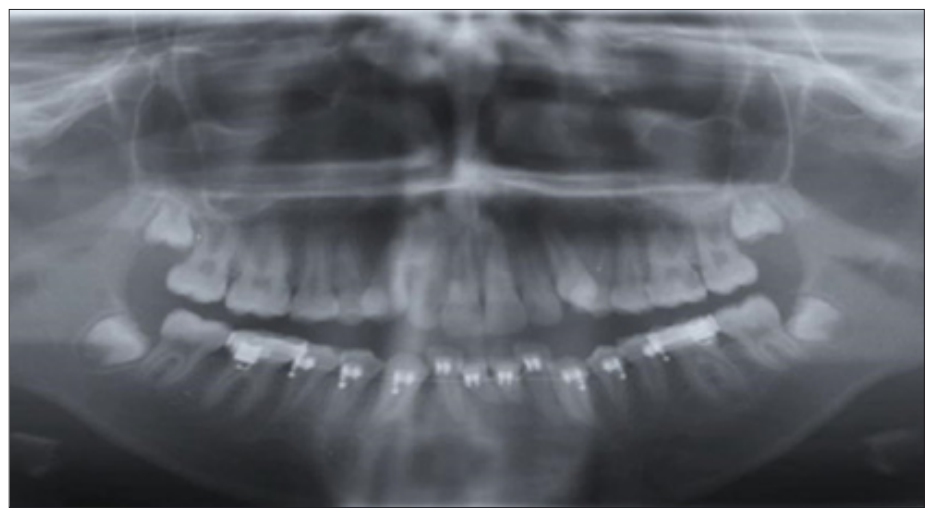

Figure 3: Pretreatment panoramic radiograph.

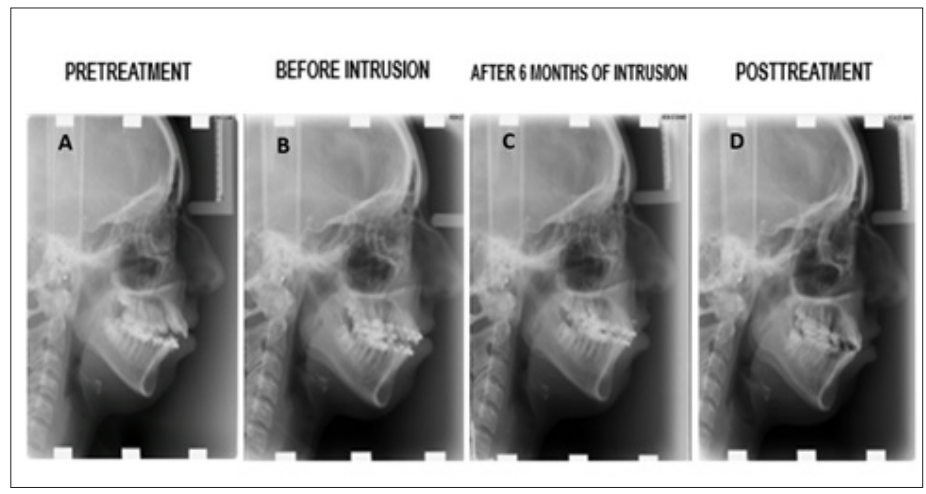

Figure 4: Lateral cephalograms. A, Pretreatment. B, Before Intrusion. C, After 6 Months of Intrusion.D, Posttreatment.

\section{Treatment objectives}

Treatment objectives that we plan to achieve for this patient at the end of treatment were a balanced occlusion, acceptable esthetics, in the front region, and correcting of canine and molar relationships by solving the crowding. The aim of this treatment was closing the patient's open bite and obtain the counterclockwise rotation of the mandible (autorotation). Initially, fixed orthodontic appliances used for creating ideal overjet and overbite. Improving the smile esthetics would be achieved by decreasing the gingival exposure (gummy smile) or not get it worst.

\section{Treatment alternatives}

The patient was informed about the optimal treatment alternative was orthognathic surgery. First option consisted of bimaxillary advancement and maxillary total impaction surgery was suitable for this case because of maxillary vertical excess, high angle growth pattern, retrognathic mandible and gummy smile. This option was not preferred; since the patient refused the surgery, we must think other options [13]. The second option consisted of extraction upper and lower first premolars can help to correct crowding but not improve facial appearance. Because of this, it 
was not desirable [14]. The third option was extraction of upper and lower second premolars provide more improvement about closing her mouth, but it gets difficult to relieve the crowding and ideal incisor inclination [15]. The fourth alternative was extraction of upper and lower first molars was more suitable for decreasing the steep mandible angle but again resolving the crowding was difficult; so, this option was not chosen [16]. The chosen option for the treatment was using intrusion mechanics to help getting autorotation of mandible and closing the mouth [17]. It can be done by several ways for example miniscrews, miniplates, zygomatic implants. Miniscrews were preferred because of easy insertion [18]. Treatment applications and publication of the records were approved by the patient and her family.

\section{Treatment progress}

Transfer patient who was 13 years 2 months presenting with anterior and lateral open bite, long face syndrome, respiratory problems came to the clinic for orthodontic evaluation. She had already have lower braces when she came to our clinic. After having a good oral hygiene at periodontics department, the patient was sent back to the orthodontics department. After the lower brackets removed the new brackets were placed on both arches together. Roth 0.018-inch (Ormco Corp.) brackets were used for this patient. A $0.014 \mathrm{NiTi}$ arch wire was inserted to achieve leveling and alignment (Figure 5). Relieving the crowding in an easy way we decide to extract upper and lower first premolars $(14,24,34,44)$. After 4 months, a $0.016 \mathrm{NiTi}$ wire was in both upper and lower arches for transverse arch development. 3 months later, a $0.014 \times 0.025$ Copper NiTi wire was inserted in both jaws to correct root angulations and achieving rotation control (Figure 5). After 4 months, a 0.016 $\times$ 0.025-Copper NiTi arch wire was used in the upper and lower arches to start correcting torque, and for the applying of stainless steel (SS) wire and to continue arch form development. Retraction of lower and upper incisors and getting ideal incisors inclination was achieved. After one appointment of applying the stabilization $0.017 \times 0.025$-inch stainless steel (SS) arch wire 4 miniscrews (2 for buccal,2 for palatal side ORLUS-1.8mm diameter $8 \mathrm{~mm}$ long) were used for intrusion of maxillary molars. Getting autorotation of mandible, taking "B" point to the forward position miniscrews were used. Self-tapping orthodontic miniscrews were progressively inserted into the palatal and vestibular bone between first and second molars with a hand screwdriver. $2 \mathrm{~mm}$ diameter ss wire was bonded to the occlusal surface of upper molars to transmit the force. $120 \mathrm{~g}$ of force was applied bilaterally with elastic chains between the head of the miniscrews (Figure 6). Also 1 miniscrew (ORLUS-1, 6mm diameter $6 \mathrm{~mm}$ long) was inserted between central incisors (11-21) for controlling the elongation of incisors because of gummy smile. It was attached to main arch wire passively by a ligature. The miniscrew which was inserted between right and left central incisors attached to main arch wire passively by a ligature because of controlling the elongation of incisors by changing the center of rotation. Molar intrusion for autorotation and open bite correction took six months of treatment (Figure 6). The objectives related to orthodontic treatment, which included solving the crowding, obtaining molar intrusion for autorotation and open bite correction had been achieved after 21 months of treatment. At the end of the treatment, upper and lower orthodontic brackets were removed, and fixed lingual retainers were placed. Vacuum-formed retainers (VFR) also were used to support the retention in the both mandibular and maxillary aches.

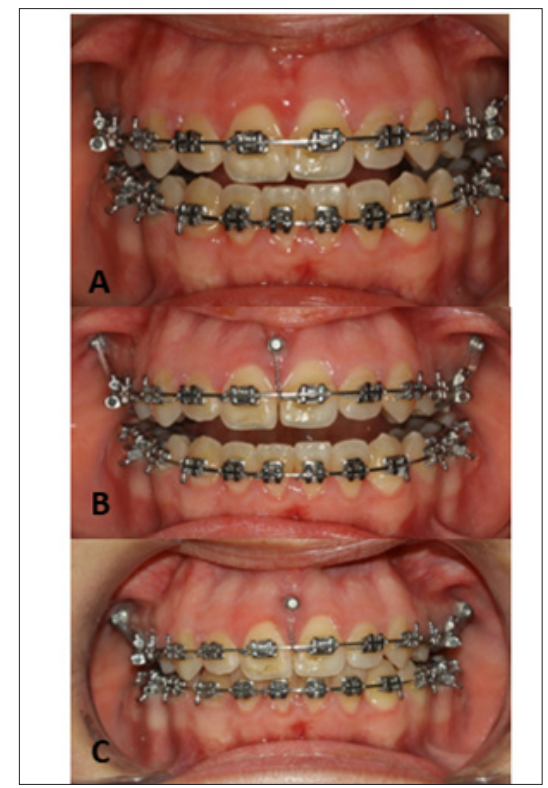

Figure 5: Treatment progress. A, Leveling and aligning phase of treatment. B, after one appointment of applying the stabilization arch wire (17x25SS) 4 miniscrew ( 2 for buccal,2 for palatal side ORLUS $-1.8 \mathrm{~mm}$ diameter $8 \mathrm{~mm}$ long) were used for intrusion of maxillary first and second molars. Also 1 miniscrew (ORLUS-1,6mm diameter $6 \mathrm{~mm}$ long) was inserted between central incisors for controlling the elongation of incisors because of gummy smile. C, After six months of intrusion. 


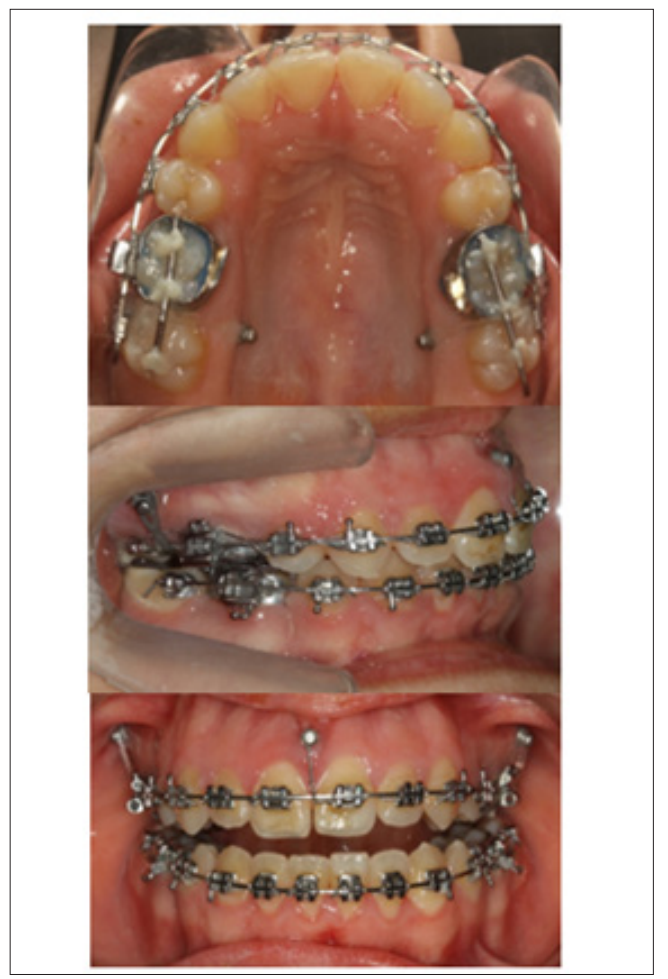

Figure 6: Self-tapping orthodontic miniscrews were progressively inserted in the palatal and buccal bone between first and second molars. $2 \mathrm{~mm}$ ss wire was bonded to the occlusal surface of upper molars to transmit the force. $120 \mathrm{~g}$ of force was applied bilaterally with elastic chains between the head of the miniscrews. 1 miniscrew was inserted between the upper incisors. It was attached to main arch wire passively by a ligature.

\section{Result}

The post-treatment facial photographs showed that the patient was satisfied with the outcome of facial aesthetics. Macro esthetics and micro esthetics were achieved (Figure 7). Lip muscle activity was a little bit high and there was also an acceptable mental muscle hyperactivity. Normal overjet and overbite relationships were achieved. The skeletal class II relationship was corrected, mandibular autorotation was obtained, leveling and alignment was achieved, and a balanced occlusion was obtained (Figure 8). Open bite was corrected, normal incisal relationship and normal canine guidance were obtained. The outcome of posttreatment panoramic graph displayed an acceptable root parallelism (Figure 9). No sign of root resorption was evident. Retention was done both by canine to canine bonded fixed retainer and a vacuum formed retainer (VFR). Facial, dental esthetics, and dental stability mostly maintained during the 5-year retention period (Figure $4 \& 10$ ). There are some changes in occlusion (mild relapse) but patient remained without any symptom during the post-treatment period.

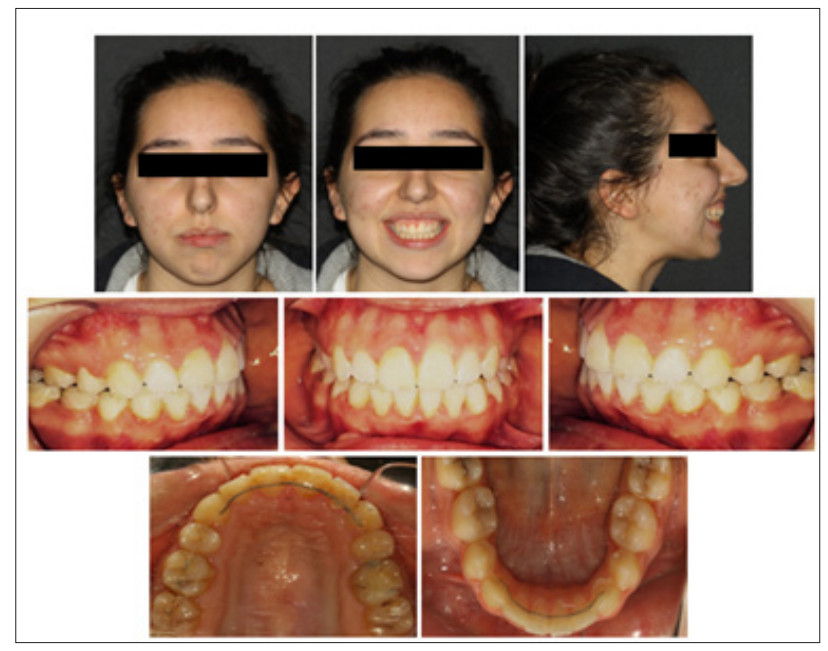

Figure 7: Post-treatment photographs. 


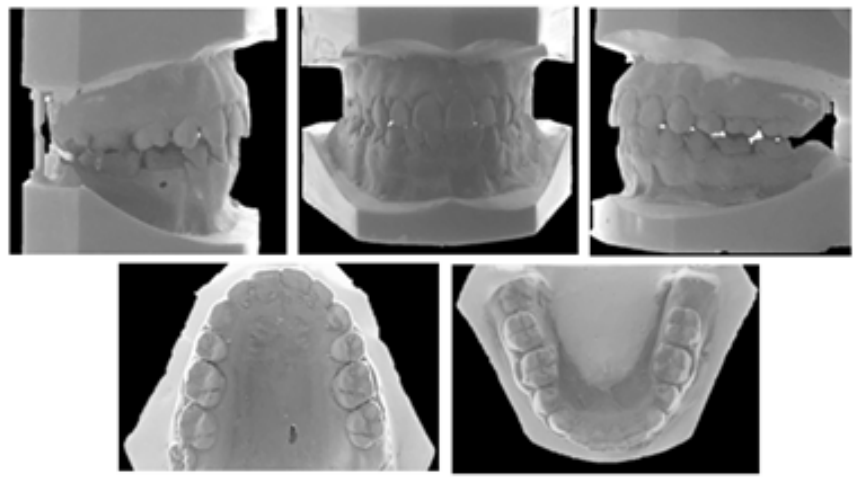

Figure 8: Post-treatment dental casts.

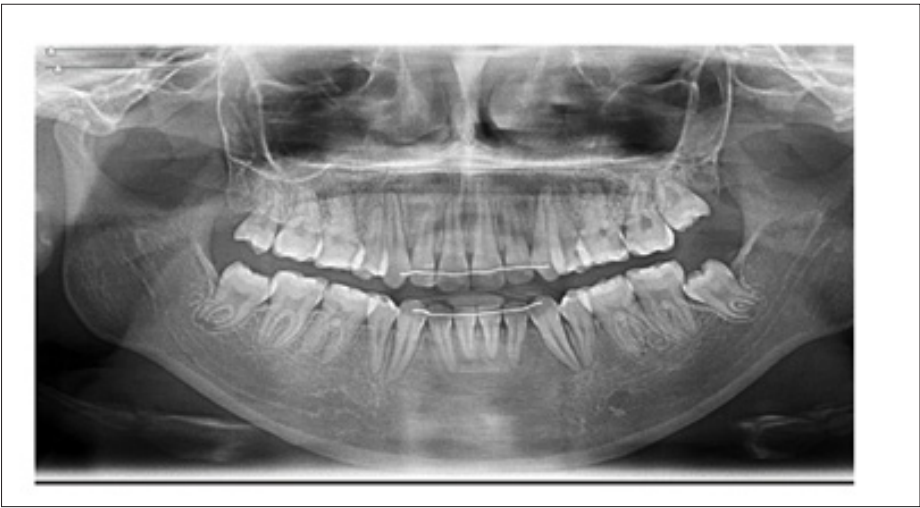

Figure 9: Post-treatment panoramic radiograph.

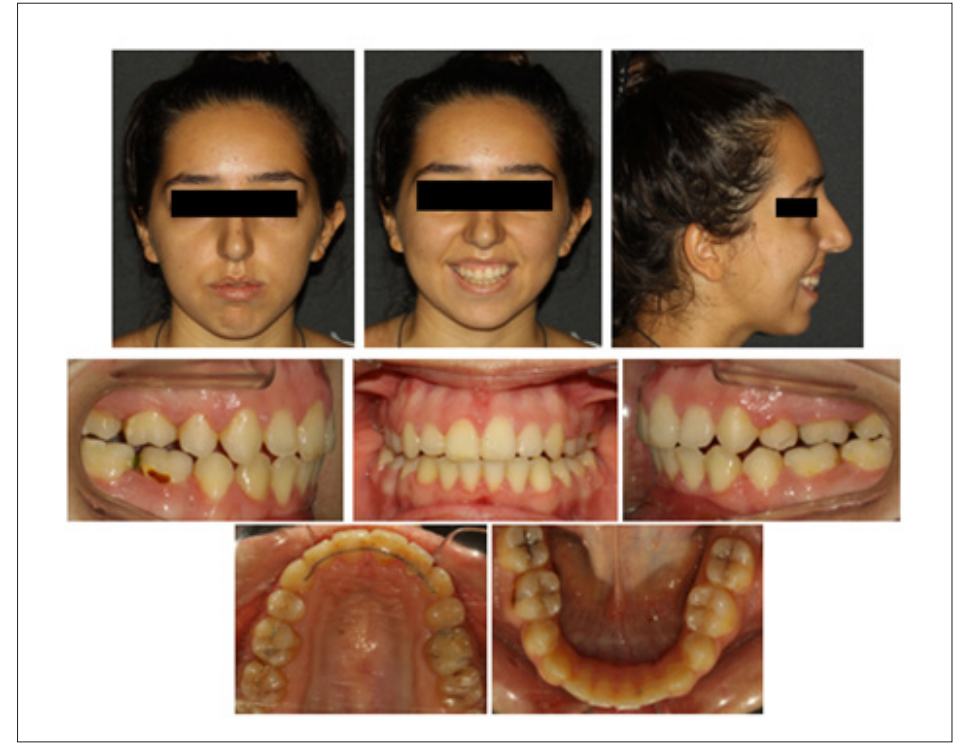

Figure 10: Intraoral and extraoral photographs at 5-year retention.

\section{Discussion}

Because of overgrowth the posterior dentoalveolar region in the maxilla and mandible; anterior open bite can occur [19]. Previous studies displayed that molar intrusion by TADs was an efficient treatment choice in patients with anterior open bite and gummy smile providing molar intrusion, counterclockwise rotation of the mandible, and correction of open bite without incisal elongation; hence, this option was chosen for treating the patient to correct the anterior open bite and to reduce the appearance of gummy smile via using miniscrew anchorage [20,21]. According 
to the study which was done by Xun et al. [22] showed that miniscrews can intrude both maxillary and mandibular molars by an average of $1.8 \mathrm{~mm}$ and $1.2 \mathrm{~mm}$. This measurement can lead to a counterclockwise rotation of the mandible. In this case, maxillary molars were intruded by $1.7 \mathrm{~mm}$ and FMA decreased by $1.2^{\circ}$. It was showed that the mandibular plane angle was reduced by $4.6^{\circ}$, which provide a counterclockwise rotation of the mandible with a decrease in the anterior facial height. In this case report, upper molar intrusion was necessary for the counterclockwise rotation of the mandible and effecting the appearance of gummy smile. Therefore, a treatment plan was chosen to intrude the upper molars and to prevent elongation of upper incisors using miniscrews. Localization of miniscrews depends on the required force for orthodontic treatment. In the maxilla most preferred region for miniscrew insertion is buccal alveolar bone between the molars or palatal region $[3,11]$. The palatal region is preferred for insertion of miniscrews in intrusion cases; because of containing lack of nerves and blood vessels and the distance to the molars is longer than buccal alveolar bone [11]. Both buccal and palatal miniscrews were used to obtain a force which is close to direct intrusion force. For an absolute intrusion of molars, the force should be applied from both direction (buccal and palatal direction [9,11]. In this case, intrusion of molars and inhibition of incisors elongation were achieved by miniscrews. Because of requiring minimal cooperation and achieving maximum anchorage for treatment make miniscrews most preferred treatment option [23,24]. Subtelny \& Sakuda [25] mentioned at their study that if patient has a real skeletal open bite, treating the patient with conventional orthodontics is impossible [25].

If patient has a skeletal class II open bite with a long anterior facial height can be treated by the intrusion of molar teeth. Sugawara et al. showed that during intrusion of the posterior teeth, mandibular plane angle and ANB were reduced at the same time the overbite and Wits appraisal were increased and a closing counterclockwise rotation of the mandible occurred [3]. If intrusion was applied by sectional force application, the in and out position (first order), mesial distal angulation (second order) and posterior torque (third order) of molars and the arch form integrity are very difficult to maintain. In order to prevent a buccal tipping full arc mechanic was applied and no sectional intrusion method was chosen for this case with the stabilizing anterior force. As shown by the results, this method can be found successful $[11,12,26]$.

Vertical control of orthodontic treatment has always been an issue that needs to be emphasized during whole treatment. Most researchers used miniscrews as an absolute anchorage for molar intrusion $[4,9,19,27]$. Extraction and molar mesialization do not always effectively provide vertical control. In this study both relieving the crowding and decreasing the vertical height extraction of premolars was done. But it was not enough for controlling and treating the vertical problem of the patient.

For this reason, miniscrew-assisted molar intrusion was applied to this high-angle patient for effectively control the posterior dentoalveolar dimensions and affording significant improvements for overall facial profile [12]. Extraction of the 4 premolars and retraction of the incisors may become deeper anterior overbite. Clockwise rotation of the maxillary anterior segment prevents of correction of gummy smile. Gummy smile can be corrected by intrusion of maxillary incisors, but this be worsening the open bite. Posterior vertical control was achieved by maxillary molar intrusion and this rotate the occlusal plane. A midpalate absolute anchorage was used to correct the anterior open bite without worsening the gummy smile and to obtain an appropriate anterior overbite. One miniscrews was used to gently intrude mostly hold the maxillary incisors to improve the gummy smile $[28,29]$. Stability of molar intrusion after treatment change between 10\% and 30\% [30]. The most relapse occurred also during the first year was reported. In this case, a slight relapse was observed but occlusion was still stable during the 5-year retention period.

\section{Conclusion}

This case report demonstrates successful treatment with orthodontic miniscrews in severe high angle with mandibular retrusion, gummy smile, open-bite closure with Class II correction. Although we obtain more aesthetic results in surgery, but miniscrews might be used for the comprehensive treatment. Minimal patient compliance is required for this camouflage technique and is particularly useful to treat high-angle skeletal patients who refuse to have surgery. All treatment outcomes of patient were stable after 5 year; however, the patient should be monitored for longer periods.

\section{References}

1. Gurton AU, Akin E, Karacay S (2004) Initial intrusion of the molars in the treatment of anterior open bite malocclusions in growing patients. Angle Orthod 74(4): 454-464.

2. Gonçalves JR, Cassano DS, Wolford LM, Santos Pinto A, Márquez IM (2008) Postsurgical stability of counterclockwise maxillomandibular advancement surgery: effect of articular disc repositioning. J Oral Maxillofac Surg 66(4): 724-738.

3. Sugawara J, Baik UB, Umemori M, Takahashi I, Nagasaka H, et al. (2002) Treatment and Posttreatment dentoalveolar changes following intrusion of mandibular molars with application of a skeletal anchorage system (SAS) for open bite correction. Int J Adult Orthodon Orthognath Surg 17(4): 243-253.

4. Sherwood KH, Burch JG, Thompson WJ (2002) Closing Anterior open bites by intruding molars with titanium miniplate anchorage. Am J Orthod Dentofacial Orthop 122(6): 593-600.

5. Wehrbein H, Feifel H, Diedrich P (1999) Palatal implant anchorage reinforcement of posterior teeth: a prospective study. Am J Orthod Dentofacial Orthop 116(6): 678-686.

6. Costa A, Raffaini M, Melsen B (1998) Miniscrews as orthodontic anchorage: a preliminary report. Int J Adult Orthod Orthognath Surg 13(3): 201-219.

7. Kanomi R (1997) Mini implant for orthodontic anchorage. J Clin Orthod 31(11): 763-767.

8. Polat Ozsoy O, Arman Ozcirpici A, Veziroglu F (2009) Miniscrews for upper incisor intrusion. Eur J Orthod 31(4): 412-416. 
9. Kaku M, Kojima S, Sumi H, Koseki H, Abedini S, et al. (2012) Gummy smile and facial profile correction using miniscrews anchorage. Angle Orthod 82(1): 170-177.

10. Migliorati M, Drago S, Dalessandri D, Lagazzo A, Gallo F, et al. (2018) On the stability efficiency of anchorage self-tapping screws: Ex vivo experiments on miniscrew implants used in Orthodontics. J Mech Behav Biomed Mater. 81: 46-51.

11. Park YC, Lee HA, Choi NC, Kim DH (2008) Open bite correction by intrusion of posterior teeth with miniscrews. Angle Orthod 78(4): 699710.

12. Wang XD, Zhang JN, Liu DW, Lei FF, Liu WT, et al. (2017) Nonsurgical correction using miniscrew-assisted vertical control of a severe high angle with mandibular retrusion and gummy smile in an adult. Am J Orthod Dentofacial Orthop 151(5): 978-988.

13. Park JH, Papademetriou M, Gardiner C, Grubb J (2019) Anterior open bite correction with 2-jaw orthognathic surgery. Am J Orthod Dentofacial Orthop 155(1): 108-116.e2.

14. Fukui T, Kano H, Saito I (2016) Nonsurgical treatment of an adult with an open bite and large lower anterior facial height with edgewise appliances and temporary anchorage devices. Am J Orthod Dentofacial Orthop 149(6): 889-898.

15. Janson G, Rizzo M, Laranjeira V, Garib DG, Valarelli FP (2017) Posterior teeth angulation in non-extraction and extraction treatment of anterior open-bite patients. Prog Orthod 18(1): 13.

16. Kojima K, Endo T, Shimooka S (2009) Effects of maxillary second molar extraction on dentofacial morphology before and after anterior openbite treatment: a cephalometric study. Odontology 97(1): 43-50.

17. Cousley RR (2014) Molar intrusion in the management of anterior openbite and 'high angle' Class II malocclusions. J Orthod 41 Suppl 1: S39-46.

18. Chang HP, Tseng YC (2014) Miniscrew implant applications in contemporary orthodontics. Kaohsiung J Med Sci 30(3): 111-115.

19. Umemori M, Sugawara J, Mitani H, Nagasaka H, Kawamura H (1999) Skeletal anchorage system for open-bite correction. Am J Orthod
Dentofacial Orthop 115(2): 166-174.

20. Kuroda S, Sakai Y, Tamamura N, Deguchi T, Yamamoto T (2007) Treatment of severe anterior open bite with skeletal anchorage in adults: comparison with orthognathic surgery outcomes. Am J Orthod Dentofacial Orthop132(5): 599-605.

21. Kuroda S, Katayama A, TakanoYamamoto T (2004) Severe anterior openbite case treated using titanium screw anchorage. Angle Orthod 74(4): 558-567.

22. Xun CL, Zeng XL, Wang X (2007) Microscrew anchorage in skeletal anterior open-bite treatment. Angle Orthod 77(1): 47-56.

23. Kaku M, Koseki H, Kawazoe A, Abedini S, Kojima S, et al. (2011) Treatment of a case of skeletal class II malocclusion with temporomandibular joint disorder using miniscrew anchorage. Cranio 29(2): 155-163.

24. Tanaka E, Yamano E, Inubushi T, Kuroda S (2012) Management of acquired open bite associated with temporomandibular joint osteoarthritis using miniscrew anchorage. Korean J Orthod 42(3): 144-154.

25. Subtelny JD, Sakuda M (1964) Openbite: diagnosis and treatment. Am J Orthod Dentofacial Orthop 50(5): 337-358.

26. Park YC, Lee SY, Kim DH, Jee SH (2003) Intrusion of posterior teeth using mini-screw implants. Am J Orthod Dentofacial Orthro 123(6): 690-694.

27. Erverdi N, Keles A, Nanda R (2004) The use of skeletal anchorage in open bite treatment: A cephalometric evaluation. Angle Orthod 74(3): 381-390.

28. Paik CH, Park HS, Ahn HW (2017) Treatment of vertical maxillary excess without open bite in a skeletal Class II hyperdivergent patient. Angle Orthod 87(4): 625-633.

29. Kim SJ, Kim JW, Choi TH, Lee KJ (2014) Combined use of miniscrews and continuous arch for intrusive root movement of incisors in Class II division 2 with gummy smile. Angle Orthod 84(5): 910-918.

30. Baek MS, Choi YJ, Yu HS, Lee KJ, Kwak J, et al. (2010) Longterm stability of anterior open-bite treatment by intrusion of maxillary posterior teeth. Am J Orthod Dentofacial Orthop138(4): 396.e1-396.e9.

For possible submissions Click below: 